\title{
Effect of Phosphate Mine Tailings from Morocco on the Mechanical Properties of Ceramic Tiles
}

\author{
F. Boutaleb, N. Boutaleb, S. Deblij, S. El Antri \\ Hassan II University of Casablanca. Laboratory of Biochemistry, \\ Environment, \\ and Agri-Food, \\ URAC36, \\ 20650 Morocco. \\ B. Bahlaouan \\ Institut Supérieur des Professions Infirmières et des Techniques de Santé de Casablanca, \\ 20250 Maroc.
}

\begin{abstract}
The objective of this work is to study a way of recovering phosphate mine tailings from the exploitation of phosphates in the manufacture of ceramic faience products. Five formulations are studied, the dry pressing process is used to make the tiles. The formulations studied are produced by mixing the waste rock with abundant local clay in percentages which vary from 0 to $100 \%$. The materials produced are characterized by their physical properties (water absorption, shrinkage), mechanical properties (resistance to bending) and surface properties (observation by scanning electron microscopy).

The results show that the integration of phosphate mine tailings improves the mechanical properties of ceramic tiles but increases the percentage of fire shrinkage and water absorption. Nevertheless, industrial use of the waste studied with the percentages 20 and $50 \%$ in clay-based formulas could be envisaged to design ceramic faience products, in accordance with the applicable mechanical and technical requirements.

This recovery method makes it possible to manage the large quantities of mine discharges and therefore their environmental impact as well as to preserve non-renewable natural resources.
\end{abstract}

Keywords: Moroccan phosphate, mine tailings, recovery, ceramic industry, mechanical properties.

\section{INTRODUCTION}

Taking advantage of a favorable geological context, the mining industry in Morocco constitutes an important vector of economic and social development. Mining is characterized by the preponderance of phosphate, of which Morocco is leading producer, with three-quarters of the world's reserves. The phosphate deposits are found in four zones: the Khouribga zone (Plateau of OuledAbdoun), the Maskala basin (Marrakech), the Bengruerir and Youssoufia region (the Gantour basin) and the LayouneBouCraa zone $[1,2,3]$. The OuledAbdoun basin of Khouribga is among the sediment richest in phosphates. It contains $44 \%$ of the country's reserves, or around 26.8 billion tonnes of phosphate [4-7]. Following operations such as moving the dead ground and the intermediate layers very poor in $\mathrm{P}_{2} \mathrm{O}_{5}$, mining inevitably results in mine tailings. The latter is dumped in the mine area, so as not to interfere with the mining activity or generate a risk. In the absence of a sustainable management strategy, the waste rock could have direct impacts on the natural environment and on the health of the neighboring population. Pollutants can be leached into groundwater following episodes of intense rain $[3,8]$.

Several solutions for the technological development of the phosphate mining waste rock are proposed in the literature (development material, filling of open voids, substrate for revegetation on mining sites, raw material for cement and concrete), but they are prove to be inappropriate and unprofitable in the current context $[3,8,9,10]$.

This work therefore offers an easy, economical and ecological solution for the manufacture of ceramic tiles from the waste rock from phosphate mines. Our strategy aims to partially replace the clays used in the manufacture of tiles by seeking the composition that generates the products with the best physico-chemical and mechanical properties. This manufacturing route then preserves nonrenewable natural resources.

\section{MATERIALS AND METHODS}

\section{A. Preparation of mixtures}

The mine tailings of phosphate (S), which is the subject of recovery in this study, is a waste resulting from the exploitation of phosphate by the Office Chérifien du Phosphate (OCP) in the Béni-Idir area (the area of Khouribga in Morocco) (Fig 1).

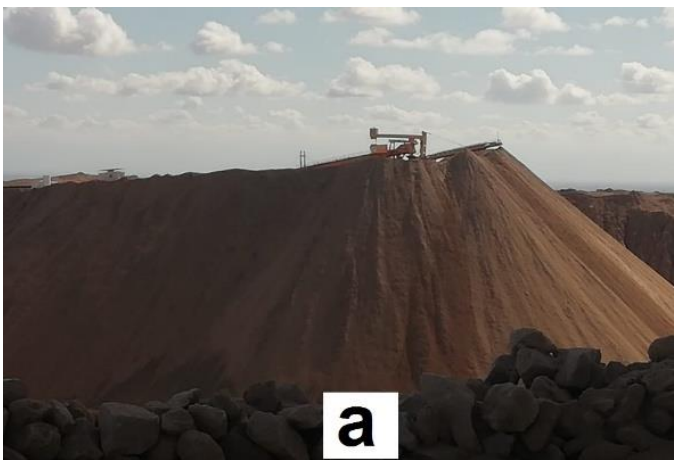




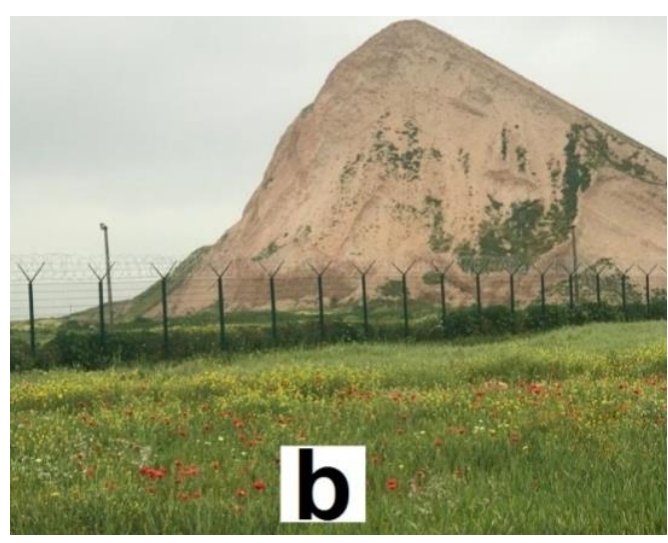

Fig 1. (a) The mine tailings of phosphate by the Beni-Idir unit of phosphate production in Khouribga (b) the contrast between fertile cultivable soil and non-cultivable old deposit of mine tailings.

For the preparation of mixtures, for the manufacture of ceramics, the mine tailings of phosphate was used in percentages ranging from 0 to $100 \%$ mixed with abundant clay from the El Gara quarry in Morocco. Five different formulations are thus prepared and studied (Table 1).

TABLE 1. THE DIFFERENT FORMULAS STUDIED.

\begin{tabular}{|l|c|c|}
\hline Formulas & \% Clay (A) & $\begin{array}{c}\text { \% Phosphate waste } \\
\text { (S) }\end{array}$ \\
\hline F1 & 100 & 0 \\
\hline F2 & 95 & 5 \\
\hline F3 & 80 & 20 \\
\hline F4 & 50 & 50 \\
\hline F5 & 0 & 100 \\
\hline
\end{tabular}

\section{B. Tile manufacturing process}

In a porcelain ball-grinding jar, with a capacity of 500 grams, the mixture is kneaded for 25 minutes, with approximately $4 \%$ water and $1 \%$ of deflocculant (Fluicer®). The slurry thus produced is placed in an industrial dryer for 30 minutes at $110^{\circ} \mathrm{C}$ until completely dry. The product obtained is ground, sieved, then rewetted by spraying.

The wet powder thus obtained is introduced into a manual tableting press. Under a constraint of 200 bars, several pellets are generated (ten for each formula). These are dried at $170^{\circ} \mathrm{C}$ for 25 minutes in an industrial roller drier. This achieves a residual water content of less than $1 \%$, a favorable condition to avoid cracks during cooking. A final stage of cooking is carried out, it lasts approximately 40 minutes, during this stage the temperature gradually reaches $1200^{\circ} \mathrm{C}$.

\section{Chemical and particle size characterisation}

The chemical analysis for the determination of the oxides is carried out by X-ray fluorescence using a Tiger S8® Brüker spectrometer [11]. The particle size analysis is carried out by dry sieving for the fraction sandy and sedimentation for silty and clay fractions $[12,13]$

\section{Mechanical characterization of the manufactured tiles}

The mechanical resistance of the manufactured tiles is made by three-point bending tests by a Shimadzu ${ }^{\circledR}$ singlecolumn tensile testing machine, EZ LX series ( 7 tests for each formula) $[14,15]$.

Cooking removal is carried out using an industrial rotary oven and measuring the dimensions of the materials before and after cooking using an electronic caliper in accordance with the Moroccan standard NM ISO 10545-3 (2017) [16]. The percentage of water absorption is carried out by weight difference before and after immersion in boiling water (100 $\left.{ }^{\circ} \mathrm{C}\right)$ for 4 hours according to the Moroccan standard NM ISO 10454-3 (2017) [16].

\section{E. Microscopic observation of tiles}

The surface analysis was carried out by SEM scanning electron microscopy observations. This analysis makes it possible to assess the granular compactness and cohesion. Microscopic observations are made by a Hirox SH-4000M device after metallization of the surfaces.

\section{RESULTS AND DISCUSSION}

A. Chemical analysis

Table 2 presents the results concerning the chemical characterization by X-ray fluorescence spectrophotometry of clay A and mining waste $S$.

TABLE 2. CHEMICAL COMPOSITIONS BY X-RAY FLUORESCENCE (IN MASS \%) OF CLAYS A AND MINING WASTE S

\begin{tabular}{|c|c|c|}
\hline & $\mathbf{A}$ & $\mathbf{S}$ \\
\hline $\mathrm{SiO}_{2}$ & 64.00 & 7.41 \\
\hline $\mathbf{A l}_{\mathbf{2}} \mathbf{O}_{3}$ & 15.15 & 0.71 \\
\hline $\mathrm{Fe}_{2} \mathrm{O}_{3}$ & 5.23 & 0.32 \\
\hline $\mathrm{CaO}$ & 2.23 & 46.45 \\
\hline MgO & 1.70 & 1.25 \\
\hline $\mathrm{K}_{2} \mathrm{O}$ & 4.28 & 0.14 \\
\hline $\mathrm{Na}_{2} \mathrm{O}$ & 0.80 & 0.57 \\
\hline$\overline{\mathbf{P}_{2} \mathbf{O}_{5}}$ & 0.10 & 24.13 \\
\hline $\mathrm{SO}_{3}$ & 0.12 & 1.06 \\
\hline $\mathrm{TiO}_{2}$ & 0.65 & 0.10 \\
\hline MnO & 0.09 & 0.02 \\
\hline $\mathrm{BaO}$ & 0.18 & 0.02 \\
\hline FL* & 6.27 & 17.06 \\
\hline
\end{tabular}

The chemical analysis (Table II) of the mining waste shows high $\mathrm{CaO}(46.45 \%)$ and $\mathrm{P}_{2} \mathrm{O}_{5}(24.13 \%)$ contents, against a low percentage of silica $\mathrm{SiO}_{2}(7.41 \%)$ and alumina $\mathrm{Al}_{2} \mathrm{O}_{3}$ $(0.71 \%)$ The high $\mathrm{CaO}$ content reflects the carbonate nature of the waste, confirmed by a considerable fire loss (17.06\%). According to the literature, the presence of carbonates stabilizes the acid-base environment and can lead to the formation of refractory monolith, essential for thermal resistance [3]. On the other hand, the presence of alumina in clay materials, generally helps to have a low shrinkage during drying, or even during baking, and allows the manufacture of refractory materials after the passage at high temperature. It is therefore essential to use the sterile mixture with clays rich in alumina to have a balanced clay mixture. 


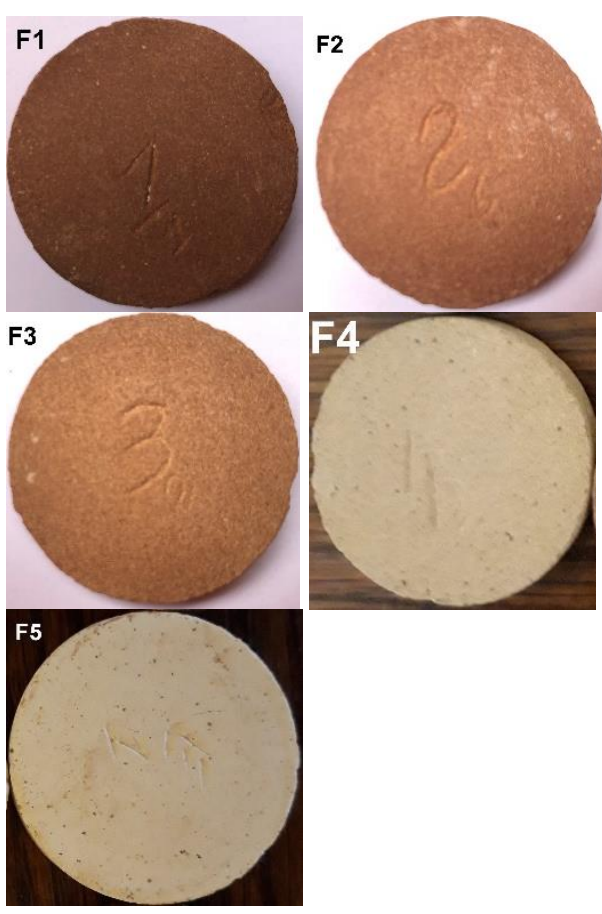

Fig 2. Photo of the materials produced

A relatively high value in $\mathrm{SO}_{3}$ is noted for the phosphate mining waste, the presence of this element reflects the richness of the environment in plastic materials [17], which plays an important role in improving plasticity [18].

\section{B. Particle size analysis}

The particle size analysis makes it possible to define various classes of materials regardless of their chemical composition. Table 3 presents the particle size distributions of components $\mathrm{S}$, and $\mathrm{A}$.

TABLE 3. GRANULOMETRY OF THE PHOSPHATE MINING WASTE (S) AND THE CLAY (A).

\begin{tabular}{|l|c|c|c|}
\hline & $\begin{array}{c}\text { Sand } \\
50-2000 \mu \mathrm{m}\end{array}$ & $\begin{array}{c}\text { Silt } \\
2-50 \mu \mathrm{m}\end{array}$ & $\begin{array}{c}\text { Clay } \\
<2 \mu \mathrm{m}\end{array}$ \\
\hline $\mathbf{S}$ & $8 \%$ & $17 \%$ & $75 \%$ \\
\hline $\mathbf{A}$ & $28 \%$ & $18 \%$ & $54 \%$ \\
\hline
\end{tabular}

The particle size analysis (Table 3 and Fig 3.) allows to classify the mining waste and clay A, among the category of fine clays according to the conventional classification of the United States Department of Agriculture [12-13]. This type of soil is characterized by strong plasticity in the wet state or compactness in the dry state.

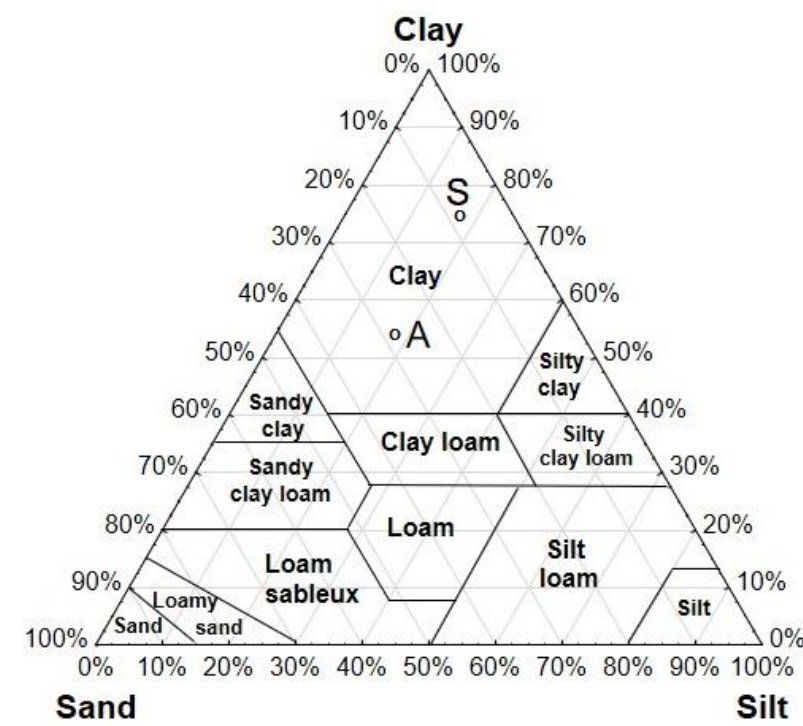

Fig 3. Classification of the components A and S according to USDA soil texture triangle [12].

Note: Henceforth the appellations F1, F2, F3, F4 and F5 will designate the tiles produced according to the corresponding formulations.

\section{Firing shrinkage and water absorption of ceramic tiles}

Ceramic materials have the particularity of undergoing volume variations when they are found in dry or humid environments. Depending on their structure, these modifications are more or less important. Indeed, large increases in volume can be observed (swelling phenomenon) when the water content increases, and conversely, a retraction can occur (shrinking phenomenon). On an industrial scale, this property has a considerable impact on the progress of the glazing process and on the technical adaptation of the material to changes in the surrounding climate.

In addition, ceramic tiles are classified in the beginning according to several groups. The mention of these is based on two criteria: the manufacturing method and the percentage of water absorption.

Starting from the method of manufacturing the tiles, two methods are distinguished: Method A- tiles made by extrusion and Method B- tiles made by dry pressing. We retain for our case the letter "B", to designate that these are tiles manufactured by dry pressing. In the same way, according to the percentage of absorption, ceramic tiles are classified according to three groups:

Group I - Tiles with low absorption percentage $(\leq 3 \%)$. It includes for tiles produced by dry pressing: The BIa group (absorption percentage $\leq 0.5 \%$ ) and the $\mathrm{BIb}$ group (absorption percentage $>0.5 \%$ and $\leq 3 \%$ )

Group II - Tiles with medium water absorption percentage $(>3 \%$ and $\leq 10 \%)$. It includes for the tiles produced by dry pressing: The BIIa group (absorption percentage $>3 \%$ and $\leq 6 \%$ ) and the BIIb group (absorption percentage $>6 \%$ and $\leq 10 \%$ ) 
Group III - This group includes tiles with a high percentage of absorption (> 10\%)

On the other hand, during firing, a ceramic piece undergoes a shrinkage expressed by a percentage (\%). Two types of shrinkage are evaluated: a mass shrinkage (a mass loss is caused by the release of certain volatile components; a diameter shrinkage (a loss in diameter caused by fusion of components, which tend to fill the voids existing between the particles).

TABLE 4. ASSESSMENT OF SHRINKAGE AND WATER ABSORPTION FOR THE MANUFACTURED CERAMIC MATERIALS.

\begin{tabular}{|c|c|c|c|c|}
\hline & $\begin{array}{c}\text { Mass loss } \\
(\%)\end{array}$ & $\begin{array}{c}\text { Diameter } \\
\text { loss }(\%)\end{array}$ & Ratio loss & $\begin{array}{c}\text { Water absorption } \\
(\%)\end{array}$ \\
\hline F1 & $6.7 \pm 0.63$ & $1.97 \pm 0.24$ & 3.40 & $2.3 \pm 0.15$ \\
\hline F2 & $7.96 \pm 1.69$ & $2.55 \pm 0.77$ & 3.12 & $6.4 \pm 1.73$ \\
\hline F3 & $8.84 \pm 1.07$ & $2.08 \pm 0.34$ & 4.25 & $10.3 \pm 1.77$ \\
\hline F4 & $10.7 \pm 0.76$ & $1.72 \pm 0.17$ & 6.22 & $14.5 \pm 1.47$ \\
\hline F5 & $14 \pm 1.03$ & $4.36 \pm 0.10$ & 3.19 & $18.5 \pm 2.36$ \\
\hline
\end{tabular}

According to table 4, only F5 has both considerably high Mass and diameter loss. F3 and F4 have relatively high mass shrinkages, but reduced diameters loss (the ratios being the highest 4.25 and 6.22 respectively).

Mass shrinkage is caused by the loss of volatile matter contained in the composition of the part formula during firing, this loss leads to the formation of cavities. A significant reduction in diameter is expressed when these voids are filled with particles that have undergone fusion, this compensation leads to the compaction of the part [19]. These materials have relatively maintained their shapes (reduced shrinkage diameter) but have considerably lost in mass. The density of the corresponding parts (the density) will then decrease after cooking. Demonstration of the porous aspect by microscopic observations will confirm this ascertainment.

Firing shrinkage relating to materials F1, F2, can be considered as comparable and low.

The results concerning the percentage of absorption in table IV show a significant variability, which confirms the relationship which exists between the formulation and the quality of the ceramics obtained. Note that F5 (100\% sterile) has a very high absorption percentage (18.5\%). Going from F1 to F5 the percentage of absorption knows an increase, this is probably due to the integration of the phosphate mining waste in $\mathrm{CaO}$, and poor in $\mathrm{SiO}_{2}$ and $\mathrm{Al}_{2} \mathrm{O}_{3}$.

According to table IV, F2 and F3 have a percentage of water absorption of between $6 \%$ and $10 \%$ which makes it possible to consider them, among the group BIIb; F2 has a percentage between $0.5 \%$ and $3 \%$, so it is part of the $\mathrm{BIb}$ class. F4 and F5 have a percentage that exceeds $10 \%$, they then fall into category B III $[14,20]$.

\section{Three-point bending Mechanical tests}

Fig. 4 shows results of the three-point bending Mechanical tests for the various

fabricated materials.

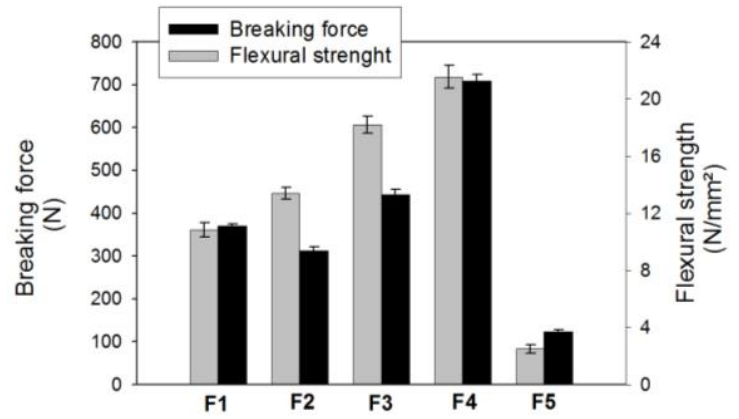

Fig 4. Three-point bending Mechanical tests for the various fabricated materials

According to the fig. 4, we note that the phosphate mining waste cannot be used alone, its use at $100 \%$ in a formula, produces an F5 material with poor mechanical properties (flexural strength of $2.5 \mathrm{~N} / \mathrm{mm}^{2}$ ). For the F1, F2, F3 and F4 clay-based formulas, the increasing integration of phosphate mining waste makes it possible to improve the mechanical properties of the manufactured tiles more and more.

For group BIII, which contains the tiles which are not necessarily the first choice from a commercial point of view, a flexural strength greater than $15 \mathrm{~N} / \mathrm{mm} 2$ is required (for a thickness $<7.5 \mathrm{~mm}$ ), so $\mathrm{F} 4$ respects this criterion and can be marketed under the name BIII.

For the BIIb group with an average absorption percentage between $6 \%$ and $10 \%$, a flexural strength of at least 18 $\mathrm{N} / \mathrm{mm} 2$ is required, so only $\mathrm{F} 3(20 \%$ of $\mathrm{S})$ meets this requirement and may be marketed according to this range $[14,20]$

For group BIb, a flexural strength greater than $27 \mathrm{~N} / \mathrm{mm}^{2}$ is required, F1 does not satisfied this criterion.

\section{E. Surface analysis of ceramic materials}

The observation of the cohesion state and the texture of the materials, carried out by scanning electron microscopy (SEM), Fig. 5 show the results.

This observation allows the detection of microcracks within the clay matrix and the decohesions at the interfaces with the aggregates.
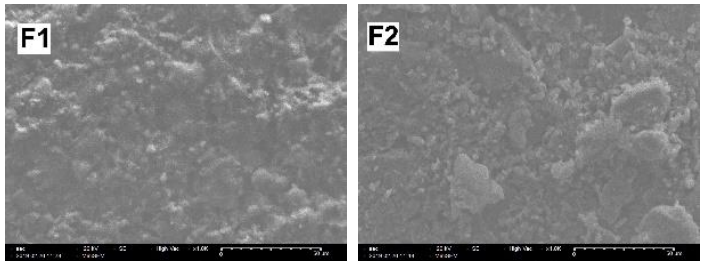

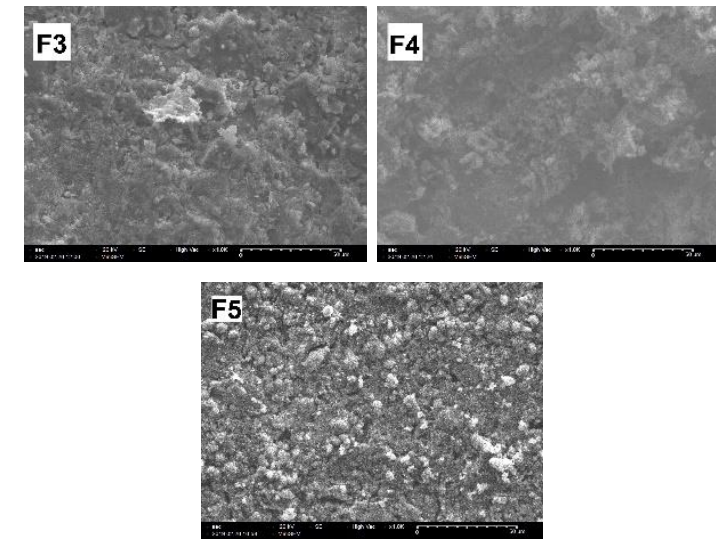

Fig 5. Observation in scanning electron microscopy at 1000X of the different ceramic materials.

The image concerning F4 shows porosity visible in SEM. This finding agrees well with the results of firing shrinkage. The firing operation causes decomposition of the volatile matter, which causes a reduction in the density of the material. On the other hand, F5 seems not very cohesive and less homogeneous, the image highlights the presence of several microcracks.

\section{CONCLUSION}

The physic-chemical and mechanical characterization shows that the phosphate mining waste cannot be used alone to manufacture tiling materials. In addition, its integration according to the $20 \%$ and $50 \%$ percentages with abundant local clay, makes it possible to produce ceramic tiles, complying with the applicable mechanical requirements. The quality control results of the tiles produced show that successful formulations can be used to design earthenware products. The recycling of phosphate discharges in the ceramic field can be one of the means of management and recovery combining ecological and economic aspects.

The use of phosphate mining waste as an alternative raw material in the ceramic industry ultimately has the advantages of:

- Reduce the cost of the local product by compensating part of the construction materials used

- Reduce the losses attached to manufacturing by improving the mechanical properties of the tiles produced

- Conserve non-renewable natural resources

- Avoid pollution

\section{ACKNOWLEDGMENTS}

To the company Espano Cerame; at the Office Cherifien du Phosphate (OCP) - Beni-Idir phosphate production and enrichment unit (Khouribga); Research Center of Materials and Energy of the Hassan II University of Casablanca.

\section{REFERENCES}

[1] HAKKOU R., BENZAAZOUA M., AND BUSSIÈRE B.:« Acid mine drainage at the abandoned Kettara mine (Morocco), 2: Mine waste geochemical behaviour», Mine Water and the Environment27: 160-170 (2008).

[2] HAKKOU R., BENZAAZOUA M., BUSSIÈRE B.:« Laboratory Evaluation of the Use of Alkaline Phosphate Wastes for the Control of Acidic Mine Drainage», Mine Water and the Environment, 28 (3) 206-218 (2009).

[3] HAKKOU R., BENZAAZOUA M., BUSSIÈRE B.: «Valorization of phosphate waste rocks and sludge from the Moroccan phosphate mines: Challenges and perspectives», Procedia Engineering $138: 110$ 118 (2016).

[4] BLEUCHOT H.: «Une ville minière marocaine : Khouribga», Revue de l'Occident musulman et de la Méditerranée, n6,pp, 29-51 (1969)

[5] ZOUHRI S., KCHIKACH A., SADDIQI O., EL HAIMER FZ., BAIDDER L., MICHARD A.: «The Cretaceous-Tertiary Plateaus», Continental Evolution: The Geology of Morocco , 116: 331-358 (2008).

[6] BARDET N., JALIL N-E., DE LAPPARENT DE BROIN F., GERMAIN D., LAMBERT O., AND AMAGHZAZ M.: «A Giant Chelonioid Turtle from the Late Cretaceous of Morocco with a Suction Feeding Apparatus Unique among Tetrapods», PLoS One 8(7): e63586, doi:10,1371/journal,pone,0063586 (2013).

[7] YANS J., AMAGHZAZ M., BOUYA B., CAPPETTA H., IACUMIN P., KOCSIS L., MOUFLIH M., SELLOUM O., SEN S., STORME Y., GHEERBRANT E.:«First carbon

[8] isotope chemostratigraphy of the OuledAbdoun phosphate Basin, Morocco ; implications for dating and evolution of earliest African placental mammals», Gondwana Research, 25 (1): 257-269 (2014) .

[9] LOUTOU M., HAJJAJI M., MANSORI M., FAVOTTO C., HAKKOU R.: «Phosphate sludge: Thermal transformation and use as lightweight aggregate material», Journal of Environmental Management 130 : 354-360 (2013).

[10] SFAR FELFOUL H., BENOUEZDOU M., CLASTRES P. : «Etude du phosphogypse de Sfax en vue d'une valorisation en technique routière», Colloque « Matériaux, Sols et Structures » MS2,Tunisie, 127-131 (2004).

[11] BOUGHZALA K., JAOUADI A., FATTAH N., BOUZOUITA K., BEN HASSINE H,: «Traitement et valorisation des rejets de phosphates de Gafsa Treatment and Valorization of Waste Gafsa pohosphate», Revue science des matériaux, Laboratoire LARHYSS 4 : 13-31 (2015) .

[12] MANNI A., ELHADDAR A., EL BOUARI A., EL AMRANI EL HASSANI I., SADIK C. : «Complete characterization of Berrechid clays (Morocco) and manufacturing of new ceramic using minimal amounts of feldspars: Economic implication», Case Studies in Construction Materials, 7: 144-153 (2017).

[13] ASTM, AMERICAN SOCIETY FOR TESTING MATERIAL (ASTM),. Standard Method for Particle-size analysis of Soil. D. 422-63 (Reapproved 1972) Annual Book of ASTM Standards. Part 19 ; $70-80$ (1974).

[14] NF EN ISO 17892-4, «Reconnaissance et essaisgéotechniques Essais de laboratoiresur les sols - Partie4 : Détermination de la distribution granulométrie des particules» (2018).

[15] NM ISO 10545-4 : «Carreaux et dallescéramique - Partie 4 : Détermination de la résistance à la flexion et module de rupture» (2017).

[16] SAWADOGO M., ZERBO L., SEYNOU M., SORGHO B. OUEDRAOGO R.: «Propriétés technologiques de carreaux céramiques A base d'argiles : influence d'un talc naturel» Chemistry\&Chemical Engineering, Biotechnology, Food Industry, 15 (3) : $231-238$ (2014).

[17] NM ISO 10545-3: «Carreaux et dallescéramique - Partie 3 : Détermination de l'absorption de l'eau, de la porositéouverte, de la densité relative et la densitéapparente» (2017) 
[18] GHARSALLI J., RKIK R., ZOUARI H., TURKI F., CHAABANE M.: " Composition and CeramicProperties of CarbonateBearing:IlliticClaysfromNorth-EasternTunisia», Verres, Céramiques \& Composites, 1 (2) : 4-15 (2011).

[19] EL YAKOUBI N., ABERKAN M., OUADIA M.:«Potentialité d'utilisation d'argiles marocaines de Jbel Kharrou dans l'industrie céramique Use potentialities of Moroccan clays from the JbelKharrou area in the ceramic industry», ComptesRendus Geoscience. 338 (10) : 693-702 (2006).

[20] CHIH-HUANG W., DENG-FONG L., PEN-CHI C.; < «Utilization of sludge as brick materials», Advances in Environmental Research, $7: 679-685$ (2003).

[21] EN 14411:2016: «carreaux céramiques - définitions, classification, caractéristiques, évaluation et vérification de la constance de performance et marquage» (2016). 